\title{
PICKLING OF Ti-Al-Si ALLOY POWDERS - A METHOD FOR IMPROVING COMPACTION WITH SPARK-PLASMA SINTERING
}

\author{
JEDKANJE PREDLEGIRANIH Ti-Al-Si PRAHOV - METODA \\ IZBOLJŠANJA ZGOŠČEVANJA MED OBLOČNIM PLAZEMSKIM \\ SINTRANJEM
}

\author{
Anna Knaislová, Pavel Novák, Filip Průša, Jan Stoulil \\ University of Chemistry and Technology, Department of Metals and Corrosion Engineering, Prague, Technická 5 , \\ 16628 Prague, Czech Republic \\ knaisloa@vscht.cz \\ Prejem rokopisa - received: 2018-03-22; sprejem za objavo - accepted for publication: 2018-05-18
}

doi:10.17222/mit.2018.054

\begin{abstract}
The work deals with the preparation of a TiAl15Si15 intermetallic alloy (w/\%), using reactive sintering, milling, pickling in selected acids and consolidation with spark-plasma sintering. After the reactive sintering, the samples were very porous. Therefore, this was followed by milling and sintering with the spark-plasma sintering (SPS) method. During the milling, oxides formed, a large amount of which suppressed the SPS consolidation, so they were removed by pickling. Improved mechanical properties were obtained by pickling the powder. Pickling in the hydrochloric acid with a concentration of $1 \mathrm{~mol} \mathrm{dm}^{-3} \mathrm{was}$ determined as the best variant. A twofold increase in the compressive strength of the alloy was achieved due to the pickling procedure.
\end{abstract}

Keywords: reactive sintering, intermetallics, hydrochloric acid

$\mathrm{V}$ raziskavi so se avtorji ukvarjali $\mathrm{z}$ intermetalno spojino TiAl15Si15. Za njeno pripravo so uporabljali reaktivno sintranje, mletje, jedkanje $\mathrm{v}$ izbranih kislinah in zgoščevanje $\mathrm{z}$ obločnim (iskrilnim) plazemskim sintranjem (SPS; angl.: spark plasma sintering). Mletju prahu in jedkanju je sledilo sintranje s postopkom SPS. Okside, ki zavirajo SPS in so nastali v veliki količini med mletjem, so odstranili. Z jedkanjem prašnih delcev so močno izboljšali mehanske lastnosti. Ugotovili so, da je najboljše jedkalno sredstvo solna kislina $\mathrm{v}$ koncentraciji $1 \mathrm{~mol} \mathrm{dm}^{-3}$. Z uvedbo faze jedkanja v postopek so dosegli dvakratno izboljšanje tlačne trdnosti zlitine.

Ključne besede: reaktivno sintranje, intermetalne spojine, solna kislina

\section{INTRODUCTION}

Intermetallic compounds are very promising materials because of their very good physical and mechanical properties, especially very good thermal stability, high melting point, excellent resistivity to oxidation and equally important low density, which predetermine intermetallics as suitable candidates for high-temperature applications, e.g., in the automobile and aerospace industry. Some applications in extreme conditions are limited by the ductility and high brittleness, especially at low temperatures. ${ }^{1}$ It must also be mentioned that they are candidates for the substitution of the conventional materials containing critical raw materials $(\mathrm{CRM}){ }^{2}$

The Ti-Al-Si alloys combine the properties of the titanium aluminide matrix and the particles of titanium silicide $\mathrm{Ti}_{5} \mathrm{Si}_{3}$. They have almost half the density compared to the common commercial heat-resistant nickel alloys. They are also highly resistant to oxidation and thermally stable while having very good mechanical properties at elevated temperatures. The temperature limit for their use is $800{ }^{\circ} \mathrm{C} .{ }^{1,3}$ Titanium aluminides TiAl and $\mathrm{Ti}_{3} \mathrm{Al}$ are characterised by a high resistance against oxidation, creep resistance and low density. The $\gamma$-TiAl has excellent mechanical properties and corrosion resistance at temperatures above $600{ }^{\circ} \mathrm{C} .{ }^{4}$

An addition of silicon to the Ti-Al matrix significantly improves the strength, ${ }^{5}$ resistance against oxidation and corrosion at high temperatures, ${ }^{6,7}$ and reactive sintering behaviour. ${ }^{8}$ The strength is improved due the formation of a very hard $\mathrm{Ti}_{5} \mathrm{Si}_{3}$ phase, which has a significant strengthening effect. Silicon also forms silica $\left(\mathrm{SiO}_{2}\right)$, which is present in the oxide layer on the surface of the material, improving the compactness and adherence of the oxide layer and initiating the formation of titanium nitride (TiN) under the oxide layer. The layers of $\mathrm{SiO}_{2}$ and $\mathrm{TiN}$ have a significant protective effect. The reason for the formation of $\mathrm{TiN}$ is the fact that silicon reduces the diffusion rate and solubility of the nitrogen in titanium. It was shown that titanium nitride does not occur in a Ti-Al alloy without the addition of silicon. ${ }^{9}$

Wider use of intermetallics limits their very complicated production. Conventional melting metallurgy is the most common preparation method nowadays. This method is very problematic because of the high melting points of intermediary phases (e.g., $\mathrm{Ti}_{5} \mathrm{Si}_{3}$ melts above $2000{ }^{\circ} \mathrm{C}$ ), the exothermic reaction during their formation, and the high reactivity of the melt with the crut 
cible. ${ }^{10,11} \mathrm{~A}$ frequent occurrence of casting defects is also a problem, in particular, the formation of cracks and pores, and poor fluidity of the melts. This method is additionally limited to hypoeutectic and eutectic Ti-Al-Si alloys only because hypereutectic alloys are very brittle due to the presence of very coarse primary silicides. ${ }^{6}$ Another problem is the processing of Ti-Al based intermetallics with mechanical forming. It is very problematic or almost impossible due to the high brittleness (low toughness) of intermetallic phases and an easy formation of the cracks on the surface of or inside a casting. It is possible to produce only relatively small shapes with a simple geometry using forming technologies. ${ }^{12}$

Another approach is the powder metallurgy, the technology dealing with the production of powders, followed by their consolidation. It can be used for almost all metals and even for very complicated shapes without the need for machining. Using this method, it is possible to combine metals with different melting points, limited solubility or different densities. It is also possible to obtain porous materials with controlled porosity. ${ }^{13}$

Especially the reactive sintering is a very suitable method for the production of intermetallics. A mixture of metal powders is compressed and heated to a temperature lower than the melting point of the produced material, which leads to the formation of intermetallic compounds. These sintering reactions are very exothermic; after reaching the initiation temperature, it is not necessary to heat up the material any further; the reaction proceeds spontaneously using its own energy and it is very fast. The process is called self-propagating hightemperature synthesis (SHS). ${ }^{14}$ In the case of the Ti-Al-Si alloys, porous products are formed using this process. ${ }^{15,16}$ A eutectic Al-Si melt is formed during sintering, which mostly fills the pores between the TiAl grains and minimizes the formation of Kirkendall porosity. ${ }^{14,15,17}$ However, certain porosity is observed after SHS, mostly in the central area of a product. ${ }^{18}$

A relatively new way of sintering is spark-plasma sintering (SPS), which allows the creation of compact materials from powders using high heating rates (even more than $300{ }^{\circ} \mathrm{C} / \mathrm{min}$ ) and short-time sintering times (usually $5-10 \mathrm{~min}$ ). The principle that is behind the production of perfectly sintered materials is that the adsorbed gases and surface oxides on the powder particles are partially removed by spark discharges, which together with high pressure cause perfect sintering of a material. ${ }^{19}$ Sintering temperatures may range from few hundreds to above $2000{ }^{\circ} \mathrm{C} .{ }^{20}$ The advantage of SPS is that it allows us to maintain a fine-grained structure, limit the crystallization processes (activated by the increasing temperature during sintering) and gain a nonporous solid material. ${ }^{21}$

The aim of this study was to prepare materials on the basis of a Ti-Al-Si system with a reduced porosity using reactive sintering, milling, acid pickling and spark-plas- ma sintering. Pickling was introduced to the process in order to improve the sintering behaviour during SPS.

\section{EXPERIMENTAL PART}

To optimize the pickling, a TiAl15Si15 alloy with the most fine-grained structure was chosen. ${ }^{22}$ Titanium powder (a purity of $99.8 \%$, a particle size $<100 \mu \mathrm{m}$ ), silicon powder (a purity of $99.99 \%$, a particle size $<20$ $\mu \mathrm{m})$ and the powder of the AlSi30 alloy (a particle size of about $100-500 \mu \mathrm{m}$ ) were blended together. The powder of the AlSi30 alloy was prepared by mechanically machining the compact AlSi30 alloy. The mixture of the powders was pressed under a pressure of $420 \mathrm{MPa}$ at room temperature. After reactive sintering at $900{ }^{\circ} \mathrm{C}$ for $30 \mathrm{~min}$, the sample was milled in a vibrating laboratory mill. At first, concentrated hydrochloric acid was chosen for the treatment of the milled powder for $10 \mathrm{~min}$. Then the powder was filtered and washed with distilled water over a Büchner funnel until approximately a $\mathrm{pH}$ value of 7 was reached. The $\mathrm{pH}$ was checked with a universal $\mathrm{pH}$ indicator ( $\mathrm{pH}$ paper).

Then the pickled powder of the TiAl15Si15 alloy was consolidated with spark-plasma sintering under a pressure of $48 \mathrm{MPa}$ at a temperature of $1100^{\circ} \mathrm{C}$ for $5 \mathrm{~min}$, with a heating rate of $100{ }^{\circ} \mathrm{C} / \mathrm{min}$, followed by 10 -minute cooling.

The phase composition was evaluated by a PANalytical X'Pert Pro diffractometer using the HighScore Plus software and the relevant PDF2 database. The microstructure was observed with an Olympus PME3 metallographic optical microscope and documented with a Carl Zeiss AxioCam ICc3 digital camera and AxioVision software. A TESCAN VEGA 3 LMU electron microscope equipped with an EDS analyser (SEM-EDS) was used for a more detailed view of the structure and identification of the present phases. The porosity and pore size were evaluated using a Lucia 4.8 image analyser.

Mechanical tests were performed on the compact samples after the spark-plasma sintering. The Vickers hardness with a load of $5 \mathrm{~kg}$ (HV 5) was measured from ten indentations into the compacted and polished samples. Tests of compressive strength were conducted in a LabTest 5.250SP1-VM testing machine. Values of the yield strength in compression were determined from the measured loading curves. The fracture toughness was measured with the Vickers indentation method on a Future-Tech FM-700 microhardness tester. The fracture toughness was calculated using Palmquist's equation (1):

$$
K_{\mathrm{c}}=0.016 \cdot\left(\frac{E}{H V}\right)^{1 / 2} \cdot\left(\frac{F}{c^{3 / 2}}\right)
$$

where $E$ is the modulus of elasticity ( $\mathrm{GPa}), H V$ is the Vickers hardness (GPa), $F$ is the load $(\mathrm{N})$ and $c$ is half of the crack length after the indention $(\mathrm{mm})$.

The abrasive-wear resistance was tested with a modified pin-on-disc method on a tribometer at room tempe- 
rature. The sample was moving on the P1200 rotating sandpaper with a load $5.8 \mathrm{~N}$ for $15 \mathrm{~min}$. The grinding distance was approximately $2.5 \mathrm{~km}$. The wear rate was calculated with Equation (2):

$$
w=\frac{\Delta m}{\rho \cdot l}
$$

where $w$ is the wear rate $\left(\mathrm{cm}^{3} \mathrm{~m}^{-1}\right), \Delta \mathrm{m}$ is the weight loss $(\mathrm{g}), \rho$ is the density of the alloy $\left(\mathrm{g} \mathrm{cm}^{-3}\right)$ and $l$ is the length of the grinding distance on the sandpaper $(\mathrm{m})$.

The average density of the Ti-Al-Si alloys $\left(4.7 \mathrm{~g} \mathrm{~cm}^{-3}\right)$ was measured with Archimedes' method.

\section{RESULTS AND DISCUSSION}

In the previous work, the preparation of the Ti-Al-Si alloys with reactive sintering and the subsequent sparkplasma sintering was described. ${ }^{8}$ The resulting structures showed improper sintering; they were considerably heterogeneous with visible boundaries between the original powders. The reason for the unconnected particles could be the oxidized surfaces of individual powder particles. Oxidization occurs during milling in a vibrating labora- tory mill. Aluminium oxide $\left(\mathrm{Al}_{2} \mathrm{O}_{3}\right)$ or titanium dioxide $\left(\mathrm{TiO}_{2}\right)$ are formed on the surfaces of particles and they obstruct a better contact and bonding of the particles during spark-plasma sintering. For this reason, the milled powders were pickled in selected acids to remove the oxide coating from the surfaces of the milled particles. Because of the corrosion resistance of titanium-based materials, it was necessary to choose a strong acid without oxidizing effects to avoid passivation.

At first, concentrated hydrochloric acid was chosen for the treatment of the milled powder of the TiAl15Si15 alloy for $10 \mathrm{~min}$. The powder of the TiAl15Si15 alloy was nearly completely dissolved; a purple extract was obtained (probably $\left(\mathrm{Ti}\left(\mathrm{H}_{2} \mathrm{O}\right)_{6}\right) \mathrm{Cl}_{3}$ ) and as the powder could not be filtered anymore, centrifuging had to be used to obtain a small amount of powder for the X-ray diffraction (XRD) analysis. XRD (Figure 1) showed that the remnants of the TiAl15Si15 alloy after the pickling in the concentrated hydrochloric acid contain no aluminium phase, but only $\mathrm{Ti}_{5} \mathrm{Si}_{3}$ silicide and silicon as a consequence of the selective dissolution of Ti from silicide. In general, aluminium oxide is not stable in an aqueous

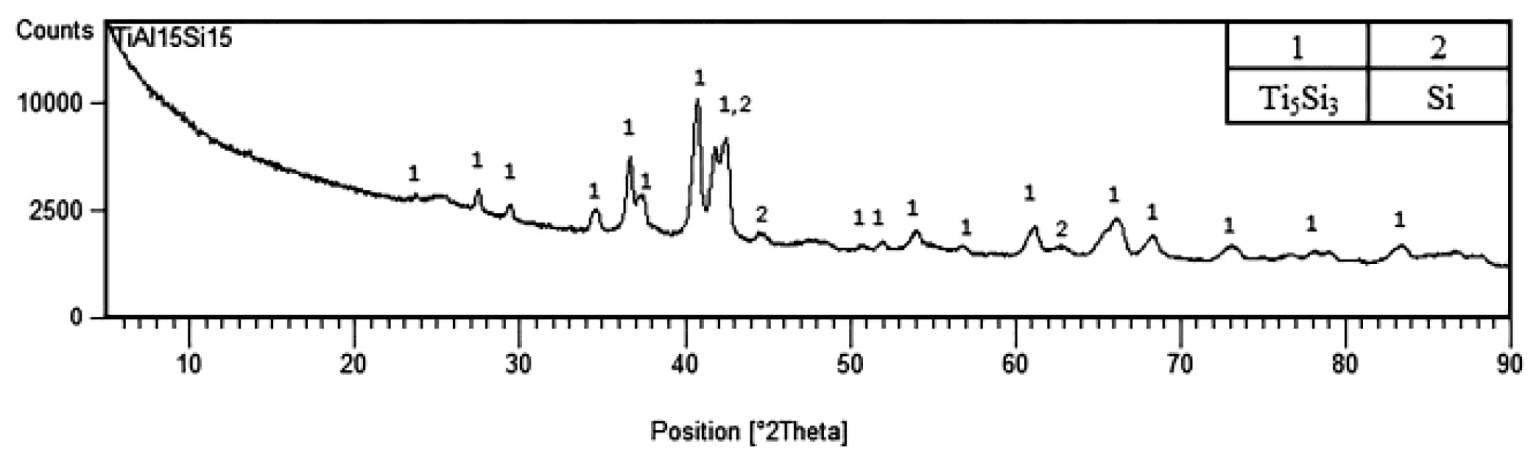

Figure 1: XRD pattern of the TiAl15Si15 alloy after pickling in concentrated hydrochloric acid

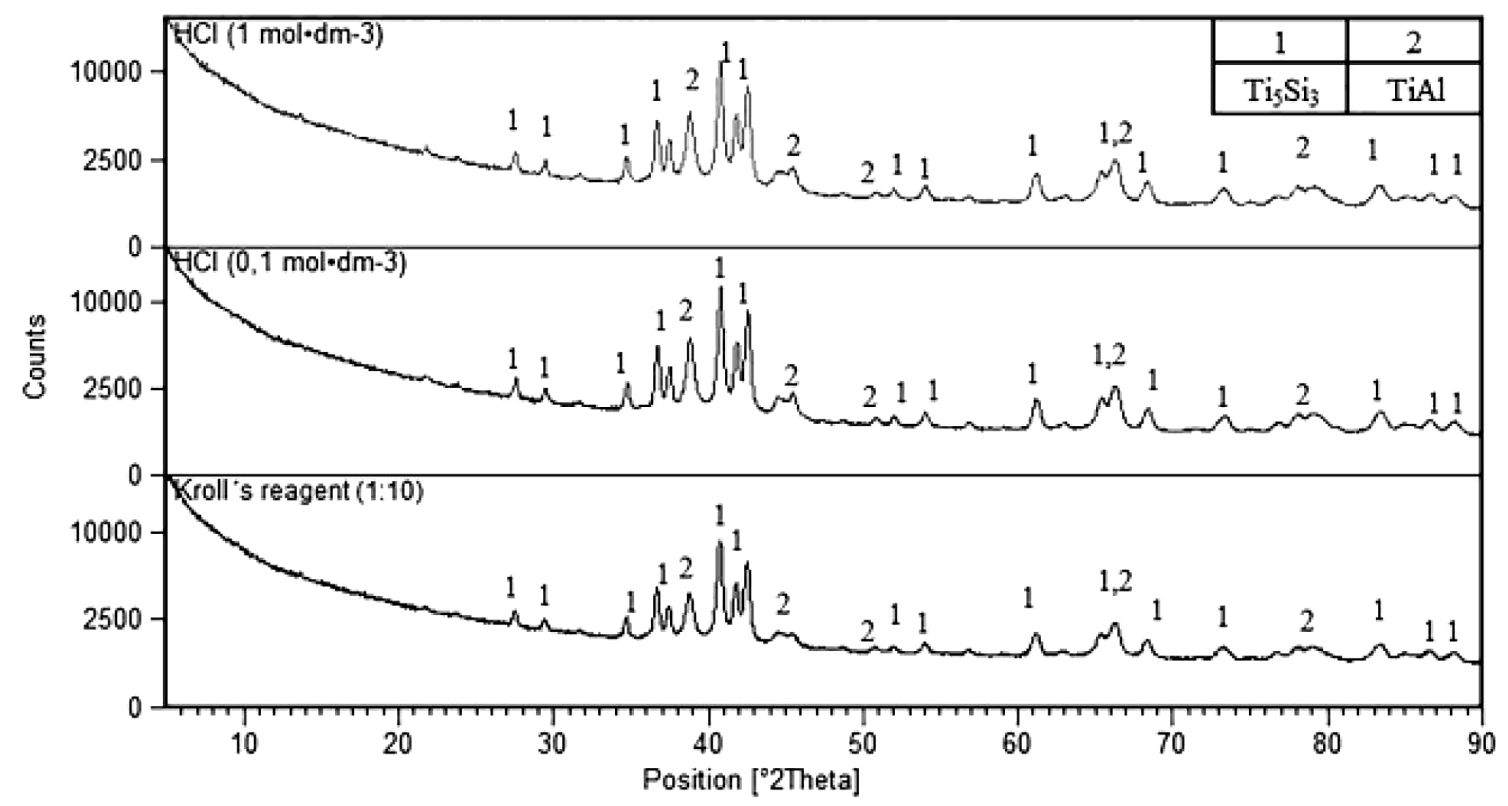

Figure 2: XRD patterns of the TiAl15Si15 alloy after pickling with selected acids 
solution with a $\mathrm{pH}$ lower than 3 . Titanium oxide can be also dissolved in strong reducing acids.

Because of an extensive dissolution of the aluminium-containing TiAl phase in a strongly acidic environment and a corresponding change of the phase composition, it was not possible to sinter the centrifuged powder with the SPS. Therefore, the pickling was then tested in a more diluted hydrochloric acid (concentrations of $1 \mathrm{~mol} \mathrm{dm}^{-3}$ and $0.1 \mathrm{~mol} \mathrm{dm}^{-3}$ ) and in modified Kroll's reagent $\left(1 \mathrm{~mL}\right.$ of $\mathrm{HF}, 0.5 \mathrm{~mL}$ of $\mathrm{HNO}_{3}$ and $98.5 \mathrm{~mL}$ of $\mathrm{H}_{2} \mathrm{O}$ ). These diluted solutions were supposed to remove the oxides and prevent an extensive dissolution of the powder. Kroll's reagent containing the hydrofluoric acid can also remove silicon oxide, and it can promote a selective dissolution of titanium from silicide.

The milled powders of the TiAl15Si15 alloy were pickled for $10 \mathrm{~min}$ and then they were filtered and washed with distilled water over a Büchner funnel. Dried powders were analysed with XRD (Figure 2). It is clear from the results that the pickling process had no effect on the final phase composition of the alloys. All the samples of TiAl15Si15 alloys contained only $\mathrm{Ti}_{5} \mathrm{Si}_{3}$ silicides in the TiAl matrix.

After the consolidation with spark-plasma sintering under a pressure of $48 \mathrm{MPa}$ at a temperature of $1100{ }^{\circ} \mathrm{C}$, the phase composition was the same as in the nonpickled sample. Merely in the TiAl15Si15 alloy pickled in diluted Kroll's reagent, pure silicon was also found, being extracted from the silicide phase.

The structure of the TiAl15Si15 alloy pickled in $1 \mathrm{~mol} \mathrm{dm}^{-3}$ hydrochloric acid and then compacted with SPS has a nearly non-porous structure with relatively well-bonded powder particles (Figure 3). Iron and nickel contamination was found in the structure, probably because of the milling in the vibratory mill (Figure 4). The presence of oxides was not detected; they were probably eliminated by acid pickling. On the contrary, the TiAl15Si15 alloy pickled in $0.1 \mathrm{~mol} \mathrm{dm}^{-3}$ hydrochloric acid was very heterogeneous and porous (black spots on Figure 3 are the pores). The matrix consisted of TiAl aluminide, containing isolated $\mathrm{Ti}_{5} \mathrm{Si}_{3}$ silicide particles.
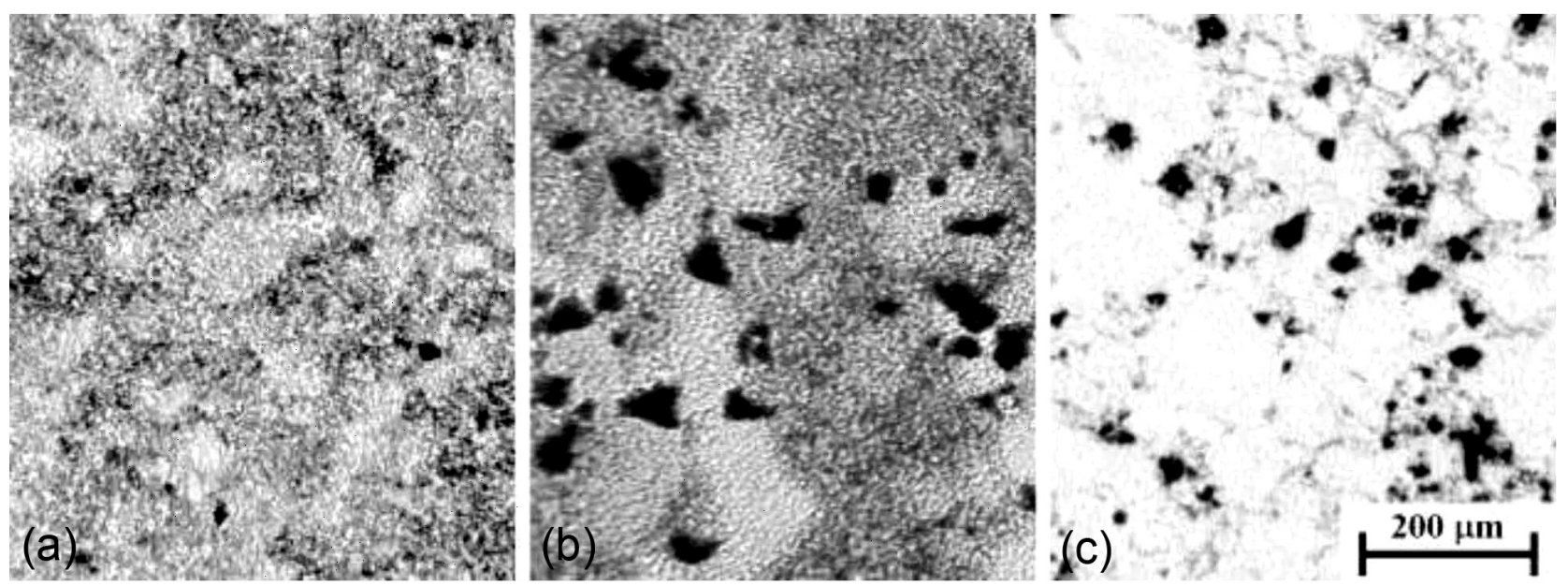

Figure 3: Microstructure of TiAl15Si15 pickled in hydrochloric acid (concentration of $1 \mathrm{~mol} \mathrm{dm}^{-3}$ ), hydrochloric acid (concentration of 0.1 mol $\mathrm{dm}^{-3}$ ) and modified Kroll's reagent

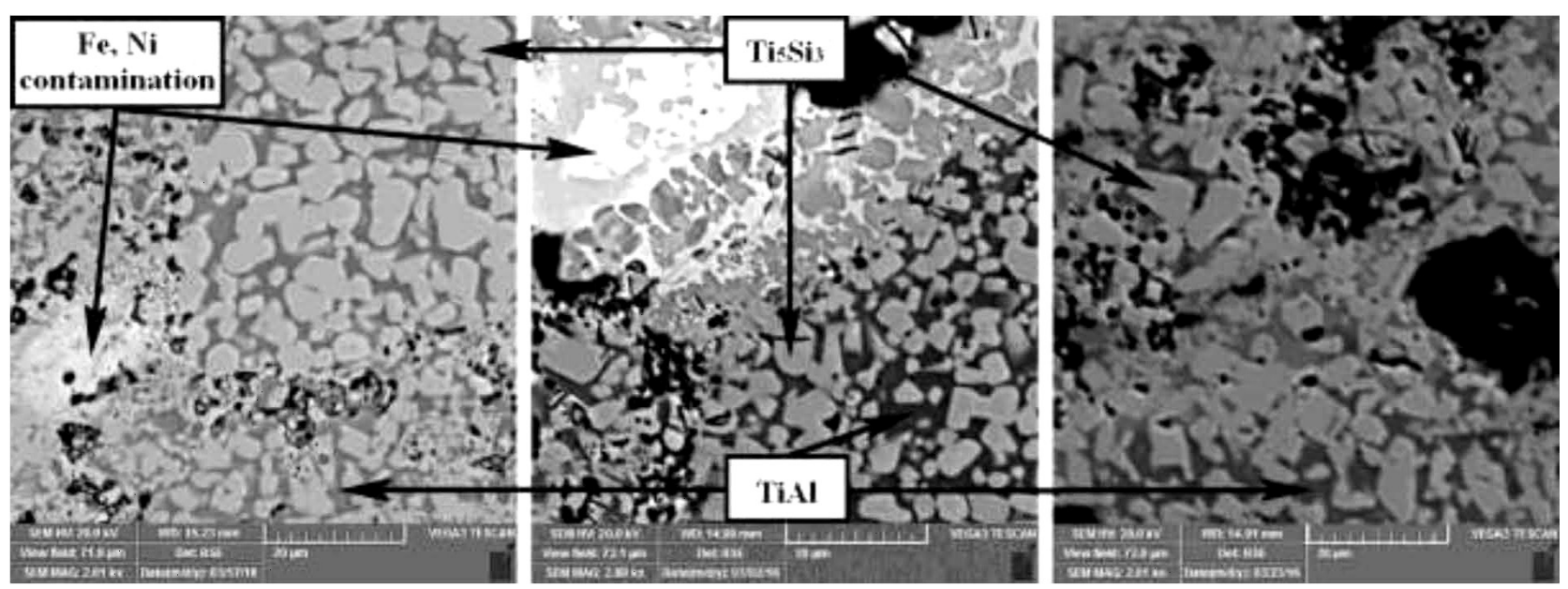

Figure 4: SEM images of TiAl15Si15 pickled in hydrochloric acid (concentration of $1 \mathrm{~mol} \mathrm{dm}^{-3}$ ), hydrochloric acid (concentration of 0.1 mol dm ${ }^{-3}$ ) and modified Kroll's reagent 


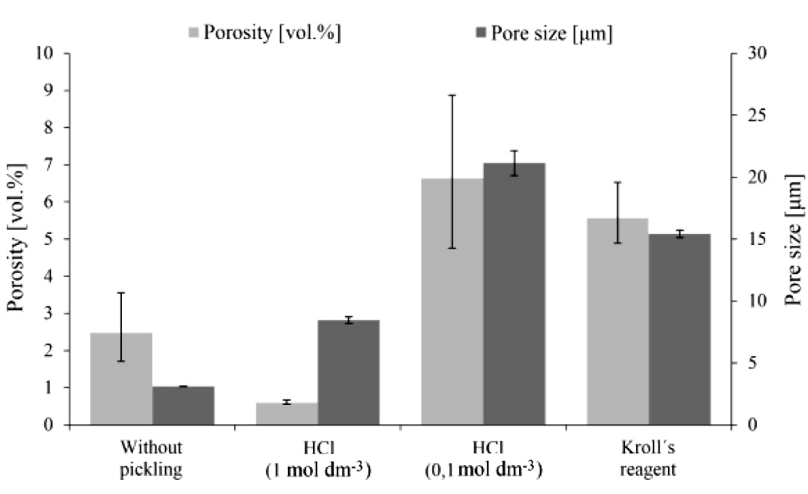

Figure 5: Porosity and pore size of the TiAl15Si15 alloy pickled in selected acids and compacted with SPS

The pickling procedure in $0.1 \mathrm{~mol} \mathrm{dm}^{-3} \mathrm{HCl}$ dissolved aluminium oxide on the TiAl particles, but it was probably not able to dissolve thick titanium oxide on silicide particles. Iron and nickel contamination was also found in the structure (Figure 4). No aluminide removal by pickling was detected. The TiAl15Si15 alloy pickled in Kroll's reagent also had a porous heterogeneous structure (Figure 3).

The TiAl15Si15 alloy prepared with reactive sintering, milling, pickling in selected acids and subsequent compaction with the SPS method was characterized by a higher porosity than the alloys prepared without pickling. ${ }^{8}$ The formation of pores was probably caused by moisture. The moistness was probably formed due to the decomposition of hydrated alumina during the compaction by spark-plasma sintering. Kroll's reagent caused the formation of pores accompanied by a partial dissolution of silicon. ${ }^{23}$ The TiAl15Si15 alloy pickled in hydrochloric acid (a concentration of $1 \mathrm{~mol} \mathrm{dm}^{-3}$ ) was found to be the most suitable as it had the lowest porosity and the smallest pore size (Figure 5). The oxidized surfaces of the particles were probably cleaned by the pickling, thereby the sinterability in the case of sparkplasma sintering was improved.

The hardness of the TiAl15Si15 alloy pickled in selected acids (Figure 6) was lower than that of the alloy without pickling. ${ }^{8}$ The reason probably lies in the removal of the oxide layer from the surfaces of powder particles. The oxide particles at the boundaries of the powders can increase the hardness, but also make the material brittle. They cause a decrease in the strength and toughness, as described below.

It can be concluded from the results that the most suitable acid for pickling TiAl15Si15 is the hydrochloric acid with the concentration of $1 \mathrm{~mol} \mathrm{dm}^{-3}$. This concentration prevents extensive dissolution of powder particles, and it is able to dissolve thick oxide layers of aluminium and titanium oxide on the TiAl and $\mathrm{Ti}_{5} \mathrm{Si}_{3}$ particles. The structure of the compacted alloy after SPS is almost non-porous, with interconnected powder particles in this case. Selected mechanical properties of this alloy were tested (Table 1).

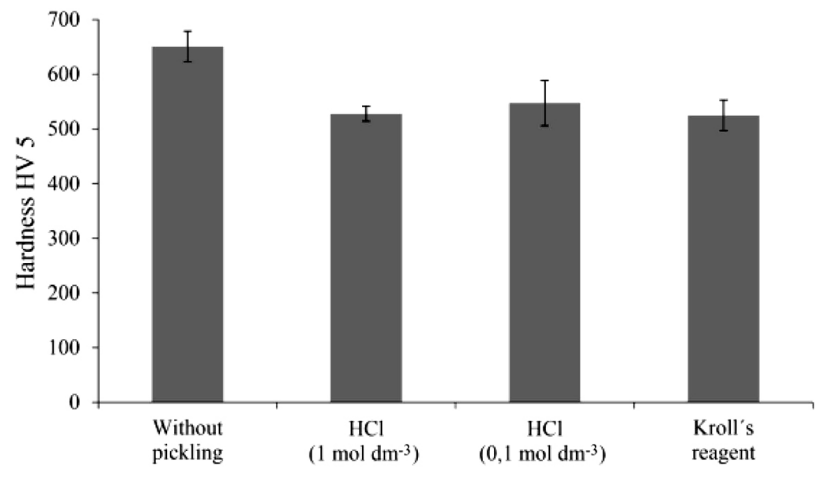

Figure 6: Hardness of the TiAl15Si15 alloy pickled in selected acids and compacted with SPS

Table 1: Comparison of mechanical properties of TiAl15Si15 pickled in an optimized agent and of the alloy without pickling

\begin{tabular}{|c|c|c|}
\hline & $\begin{array}{c}\text { TiAl15Si15 } \\
\text { (without pickling) }\end{array}$ & $\begin{array}{c}\text { TiAl15Si15 } \\
\left(\mathrm{HCl} 1 \mathrm{~mol} \mathrm{dm}^{-3}\right)\end{array}$ \\
\hline $\mathrm{UCS}(\mathrm{MPa})$ & 758 & 1510 \\
\hline $\mathrm{HV} \mathrm{5}$ & $650 \pm 49$ & $530 \pm 28$ \\
\hline$K c\left(\mathrm{MPa} \mathrm{m}^{1 / 2}\right)$ & 0,84 & 0,92 \\
\hline$w\left(\mathrm{~mm}^{3} \mathrm{~m}^{-1}\right)$ & $0,0018 \pm 0,0003$ & $0,0020 \pm 0,0002$ \\
\hline
\end{tabular}

It can be seen from the table that pickling had the greatest influence on the ultimate compressive strength (UCS), which was increased by pickling to an almost double value in comparison with the TiAl15Si15 alloy prepared without pickling. A better consolidation due to spark-plasma sintering, better bonding of powder particles and a decrease in the brittleness due to the removal of oxides helped to increase the ultimate compressive strength. The UCS value of $1500 \mathrm{MPa}$ is very high for the Ti-Al-Si intermetallic compounds.

Further, the hardness of the material was slightly reduced by the pickling, causing the removal of hard and brittle oxides and therefore the fracture toughness of the alloys slightly increased. However, the fracture toughness of the Ti-Al-Si alloys is very low (about 0.92 $\mathrm{MPa} \mathrm{m}^{1 / 2}$ ), compared to the mechanically alloyed alloys, which have a more fine-grained structure. ${ }^{24}$ The process of acid pickling of powders can be used to improve the consolidation by SPS due to a removal of oxides also in the case of atomized or mechanically alloyed powders, probably providing the same improvement.

\section{CONCLUSIONS}

Ti-Al-Si alloys were successfully prepared with a combination of reactive sintering, milling, acid pickling and consolidation by spark-plasma sintering. An improvement in the consolidation during spark-plasma sintering was achieved with the pickling of milled powders. The pickling in a concentrated hydrochloric acid removed a considerable amount of titanium and aluminium from the powders into the solution. Therefore, lower concentrations of the hydrochloric acid $\left(1 \mathrm{~mol} \mathrm{dm}^{-3}\right.$ and $0.1 \mathrm{~mol} \mathrm{dm}^{-3}$ ) and modified Kroll's reagent were 
chosen for the next experiments. The most suitable solution for pickling the TiAl15Si15 alloy before the consolidation appears to be the hydrochloric acid with a concentration of $1 \mathrm{~mol} \mathrm{dm}^{-3}$. The microstructure of the alloy prepared with SPS was almost non-porous, with strongly interconnected powder particles and without visible boundaries. A twofold increase in the ultimate compressive strength and a noticeable increase in the fracture toughness of this alloy were achieved due to pickling. From the obtained results, it is obvious that the preparation of the Ti-Al-Si alloys with powder metallurgy using reactive sintering, milling, pickling with $1 \mathrm{~mol} \mathrm{dm}^{-3}$ hydrochloric acid and the subsequent consolidation with SPS is a suitable method for the production of these intermetallic-based materials, as shown in the case of the TiAl15Si15 alloy.

\section{Acknowledgment}

This research was financially supported by the Czech Science Foundation, project no. P108/12/G043, and from the specific university research fund, MSMT No 21-SVV/2018.

\section{REFERENCES}

${ }^{1}$ Y. Kimura, D. P. Pope, Ductility and toughness in intermetallics, Intermetallics, 6 (1998), 567-571, doi:10.1016/S0966-9795(98) 00061-2

${ }^{2}$ M. Grilli, T. Bellezze, E. Gamsjäger, A. Rinaldi, P. Novak, S. Balos, R. Piticescu, M. Ruello, Solutions for critical raw materials under extreme conditions: A review, Materials, 10 (2017), 285, doi:10.3390/ma10030285

${ }^{3}$ K. P. Rao, J. B. Zhou, Characterization of mechanically alloyed Ti-Al-Si powder blends and their subsequent thermal stability, Materials Science and Engineering: A, 338 (2002), 282-298, doi:10.1016/S0921-5093(02)00095-3

${ }^{4}$ S. Kumaran, T. Sasikumar, R. Arockiakumar, T. Srinivasa Rao, Nanostructured titanium aluminides prepared by mechanical alloying and subsequent thermal treatment, Powder Technology, 185 (2008), 124-130, doi:10.1016/j.powtec.2007.10.006

${ }^{5}$ P. Novák, J. Křriž, F. Průša, J. Kubásek, I. Marek, A. Michalcová, M. Voděrová, D. Vojtěch, Structure and properties of Ti-Al-Si-X alloys produced by SHS method, Intermetallics, 39 (2013), 11-19, doi:10.1016/j.intermet.2013.03.009

${ }^{6}$ Z. Q. Guan, T. Pfullmann, M. Oehring, R. Bormann, Phase formation during ball milling and subsequent thermal decomposition of Ti-Al-Si powder blends, Journal of Alloys and Compounds, 252 (1997), 245-251, doi:10.1016/S0925-8388(96)02720-X

${ }^{7}$ J. S. Wu, P. A. Beaven, R. Wagner, The Ti3(Al, Si) + Ti5(Si, Al)3 eutectic reaction in the Ti-Al-Si system, Scripta Metallurgica et Materialia, 24 (1990), 207-212, doi:10.1016/0956-716X(90)90593-6
${ }^{8}$ A. Knaislová, P. Novák, F. Průša, Preparation of Ti-Al-Si alloys by powder metallurgy, Manufacturing Technology, 16 (2016), 1274-1278

${ }^{9}$ D. Vojtěch, M. Mort'aniková, P. Novák, Kinetic and thermodynamic aspects of high-temperature oxidation of selected Ti-based alloys, Defect and Diffusion Forum, 263 (2007), 123-127, doi:10.4028/ www.scientific.net/DDF.263.123

${ }^{10}$ P. Novák, Příprava, vlastnosti a použití intermetalických slou enin, Chemické listy, 106 (2012), 884-889

${ }^{11}$ L. Zemčík, A. Dlouhý, S. Król, M. Prażmowskic, Vacuum metallurgy of TiAl intermetallics, Metal, (2005)

${ }^{12}$ A. Lasalmonie, Intermetallics: Why is it so difficult to introduce them in gas turbine engines?, Intermetallics, 14 (2006), 1123-1129, doi:10.1016/j.intermet.2006.01.064

${ }^{13}$ S. A. Tsukerman, Introduction, Powder Metallurgy, Pergamon, 1965, VII-XI

${ }^{14}$ P. Novák, D. Vojtěch, J. Šerák, J. Kubásek, F. Průša, V. Knotek, A. Michalcová, M. Novák, Synthesis of intermediary phases in Ti-Al-Si system by reactive sintering, Chemické listy, 103 (2009), 1022-1026

${ }^{15} \mathrm{~K}$. Morsi, Review: reaction synthesis processing of Ni-Al intermetallic materials, Materials Science and Engineering: A, 299 (2001), 1-15, doi:10.1016/S0921-5093(00)01407-6

${ }^{16}$ M. Valalík, P. Novák, T. F. Kubatík, D. Vojtěch, Unconventional method of preparation intermetallic phases Fe-Al by mechanical alloying in comparison to reactive sintering, Manufacturing Technology, 15 (2015), 105-109

${ }^{17}$ D. E. Alman, Reactive sintering of TiAl-Ti5Si3 in situ composites, Intermetallics, 13 (2005), 572-579, doi:10.1016/j.intermet.2004. 09.011

${ }^{18}$ P. Novák, F. Průša, J. Šerák, D. Vojtěch, A. Michalcová, Oxidation resistance and thermal stability of Ti-Al-Si alloys produced by reactive sintering, Metal, 2009

${ }^{19}$ Z.-H. Zhang, Z.-F. Liu, J.-F. Lu, X.-B. Shen, F.-C. Wang, Y.-D. Wang, The sintering mechanism in spark plasma sintering - Proof of the occurrence of spark discharge, Scripta Materialia, 81 (2014), 56-59, doi:10.1016/j.scriptamat.2014.03.011

${ }^{20}$ M. Kermani, M. Razavi, M. R. Rahimipour, M. Zakeri, The effect of temperature on the in situ synthesis-sintering and mechanical properties of MoSi2 prepared by spark plasma sintering, Journal of Alloys and Compounds, 585 (2014), 229-233, doi:10.1016/j.jallcom. 2013.09.125

${ }^{21}$ M. Suárez, A. Fernández, J. L. Menéndez, R. Torrecillas, H. U. Kessel, J. Hennicke, R. Kirchner, T. Kessel, Challenges and opportunities for spark plasma sintering: A key technology for a new generation of materials, InTech, (2013), doi:10.5772/53706

${ }^{22}$ A. Knaislová, P. Novák, K. Nová, Using of microscopy in optimization of the Ti-Al-Si alloys preparation by powder metallurgy, Manufacturing Technology, 16 (2016), 946-949

${ }^{23}$ E. A. Starostina, V. V. Starkov, A. F. Vyatkin, Porous-silicon formation in HF-HNO3-H2O etchants, Russian Microelectronics, 31 (2002), 88-96, doi:10.1023/A:1014337308494

${ }^{24}$ J. Vystrčil, P. Novák, A. Michalcová, Preparation of ultra-fine grained alloys based on Fe-Al-Si and Ti-Al-Si intermetallic compounds by powder metallurgy using the mechanical alloying, Manufacturing Technology, 15 (2015), 238-242 